\title{
Engagement of demographers in environmental issues from a historical perspective
}

\section{Peter McDonald*}

The premise of this Demographic Debate is derived from a claim made by the IUSSP Panel on Population and Climate Change that when they were organising meetings in 2012 and 2014, very few demographers offered to contribute papers to the meetings. To further investigate this claim, I looked at the program of the 2015 meeting of the Population Association of America, the most recent international population conference. There were several sessions with the word 'environment' in the title, but after inspecting the papers in these sessions I found that that term was very broadly defined. There were papers at this PAA meeting on localised environmental issues, and, over the years, it has not been uncommon for demographers to engage in research related to localised environmental issues such as air pollution, pollution of water systems, flooding, clean water and sewerage, depletion of aquifers, soil erosion, deforestation, destruction of natural habitats, and congestion. It appears that demographers are relatively comfortable working at this localised level. But there were no sessions at the 2015 PAA meeting with 'climate change' in the title, and only five or six papers at the conference even mentioned climate change; primarily in the context of migration as an adaptation to climate change. Only one paper dealt directly with demography and climate change mitigation. Thus, the premise seems to have substance.

A historical perspective may be useful. In the late 1960s, the dominant paradigm in demography was that developing countries needed to lower their high fertility rates because this would promote economic growth as both public and private expenditures were redirected away from meeting the needs of children and towards more productive forms of economic investment. The expansion of education and of agricultural production were also components of this model, which had been developed through a series of major studies at Princeton University in the 1940s and the 1950s (see, most importantly, Coale and Hoover 1958). The model was taken up vigorously by the United States government during the Cold War as a means of combating the spread of communism. But it can also be argued that a

* Peter McDonald, Crawford School of Public Policy, Australian National University, Acton ACT 0200, Australia

Email: Peter.McDonald@anu.edu.au 
similar motivation inspired the family planning programs of China and Vietnam (Potts 2006). The remarkable economic progress made over the past 50 years in the Asian countries that followed this approach is evidence of its cogency (Bloom and Williamson 1997).

The most severe challenge to this paradigm has been an environmental protection argument that rose to prominence around 1970 known as 'limits to growth' (Ehrlich and Ehrlich 1970, Meadows et al. 1972). Ironically, both the economic growth and the limits to growth proponents were advocating zero population growth, but one side was making the argument to promote economic growth, while the other side was making the argument to slow or stop economic growth. I was a doctoral student in demography at the time when this debate arose, and I went to hear Paul Ehrlich speak when he visited the ANU (Australian National University). It is fair to say that my teachers at the time subscribed to the Princeton approach, and that they were strongly opposed to the limits to growth argument. Working in Indonesia in the 1970s, I also agreed with the economic growth through population control argument, as, I think, did most demographers. Whatever one makes of the subsequent history-including of the Simon-Ehrlich bet and the relative outcomes of the two arguments - the point that I want to make here is that the bitterness of this debate left demographers somewhat cautious about engaging with environmental issues. More cynically, it could be observed that funding in the population field was more associated with the economic growth side of the debate than with the limits to growth side.

The limits to growth argument is predominantly Malthusian; i.e. that resources are limited and that their depletion will have disastrous consequences. At the time, the issue of planet-wide climate change resulting from the burning of fossil fuels was well-established, but was still somewhat tentative (see Spengler 1960; Ehrlich and Ehrlich 1970: 239-242; and Ward and Dubos 1972, Chapter 13). Today, we as a planet have managed to deal with the resource issue, particularly the issue of energy and mineral resources, although ensuring that people have basic necessities such as food and water is a major challenge for the future, especially in poor countries with high rates of population growth. On the other hand, climate change has become the dominant scientific paradigm of the age, and very few demographers could be considered 'climate change deniers'. But as a reaction to this history of sometimes bitter controversies, centres of population research around the world, with some notable exceptions, have not invested in specialists in population and environment research. Social and economic issues dominate the policy-related agendas of population specialists, and these issues are, of course, important. My view is, however, that the balance will change and that younger demographers, not daunted by the historical tensions in population and environment research, will take up population and climate change research. This direction needs to be fostered, and I tried to do so by establishing the IUSSP Panel on Population and Climate Change. However, universities and other centres of population research should be making more appointments in this area of research. 


\section{References}

Bloom, D. and J. Williamson 1998. Demographic transitions and economic miracles in emerging Asia. The World Bank Economic Review 12(3): 419-455.

Coale, A. and E. Hoover 1958. Population growth and economic development in low income countries. Princeton: Princeton University Press.

Ehrlich, P. and A. Ehrlich 1970. Population resources environment: Issues in human ecology. San Francisco: W. H. Freeman and Company.

Meadows, D., D. Meadows, J. Randers and W. Behrens 1972. The limits to growth: A global challenge. New York: Universe Books.

Potts, M. 2006. China's one child policy: The policy that changed the world. Editorial in the British Medical Journal 333(7564): 361-2.

Spengler, J. 1960. Population and world economic development. Science 131: 1497-1502.

Ward, B. and R. Dubos 1972. Only one earth: The care and maintenance of a small planet. Harmondsworth, Middlesex: Penguin. 
